\title{
APPLICATION OF SBR TO TREAT DIFFERENT TYPES OF WASTEWATERS
}

\author{
XU, J. ${ }^{*}$-SUN, X. X. - LI, H. Y. - WANG, H. Y. - GONG, R. \\ School of Environmental Engineering, Nanjing Institute of Technology \\ Nanjing 211167, P. R. China \\ (phone: +86-25-8611-8963; fax: +86-25-8611-8974) \\ * Corresponding author \\ e-mail:xujin100408@163.com \\ (phone:+86-25-8611-8963; fax:+86-25-8611-8974) \\ (Received $3^{\text {rd }}$ Aug 2016; accepted $12^{\text {th }}$ Oct 2016)
}

\begin{abstract}
The objective of this study was to investigate the pollutant removal efficiency of different types of wastewaters by a sequencing batch reactor (SBR). A laboratory-scale SBR was used to treat sewage, medical wastewater and industrial wastewater. The effects of different conditions of aeration, stirring and settling on the efficiency of pollutants removal were explored to optimize the performance, especially for the removal of organic matter (COD), ammonia nitrogen $\left(\mathrm{NH}_{4}{ }^{+} \mathrm{N}\right)$, total nitrogen(TN) and total phosphorus(TP) of different types of polluted water. From the results it was showed that when aeration 6 hours, stirring 4 hours and settling 2 hours in SBR, the removal rates of COD, nitrogen and phosphorus of domestic sewage were 93\%, 98\% and 83\%, respectively; when aeration 5 hours, stirring 5 hours and settling 1 hour in the SBR, the removal rates of COD and nitrogen of pharmaceutical wastewater were $83 \%$ and $90 \%$, respectively; when aeration 4 hours, stirring 4 hours and settling 1 hour in the SBR, removal rates of COD, nitrogen and phosphorus of industrial wastewater were 97\%, 93\% and 97\%, respectively.
\end{abstract}

Keywords: sequencing batch reactor, activated sludge, biological treatment,COD

\section{Introduction}

Biological treatment for wastewater mainly includes aerobic, anaerobic and anoxic processes. As a high efficiency and inexpensive method to treat wastewaters, SBR technology has been widely used through the years (Mace et al., 2002). It has been also successfully emplored to treat pollutants of various types of wastewaters (Lamine et al., 2007; Giordano et al., 2005; Obaja et al., 2003; Jin et al., 2015). SBR method has some unique characteristics that is distinguished from others activated-sludge process. For example, the processes of nitrogen removal and sludge sedimentation can be carried out in the same SBR reactor, while those need be separated in other biological treatment processes $(\mathrm{Ng}, 1987)$. The SBR was not only used efficiently for organic pollutants removal of municipal wastewater, but also successfully applied in the nitrogen removal of wastewater (Silverstein and Schroeder, 1983). Microbial reactions of nitrogen removal are performed within the same SBR tank (Ketchum et al., 1997; Gali et al., 2008). It can also be applied for pollutants removal of wastewater containing a high concentration of nitrogen and organic matters (Rodríguez et al., 2011). Both anaerobic and aerobic conditions can be used for there moval of biological phosphorus in cyclic processes in a single reactor (Sarioglu, 2005). The property of combination of organic matters, nutrients (nitrogen $(\mathrm{N})$ and phosphorus $(\mathrm{P})$ ) removal in a SBR tank makes it economical prominently (Carucci et al., 1995).

The SBR biological processes are capable of achieving complete degradation of the biodegradable compounds contained in the olive mill wastewaters and therefore to significantly reduce the pollutant load. It showed high performances, achieving removal of the biodegradable 
organic content at all the investigated influent loadings, with average efficiencies constantly at about $60 \%$ and $90 \%$ for total polyphenols (TPPs) and COD, respectively (Chiavola et al., 2014).

A sequencing batch biofilm reactor (SBBR) was also used for removal of $\mathrm{N}$ and $\mathrm{P}$ from swinewastewater, resulting in excellent purification effect. The percentage removal of COD, $\mathrm{NH}_{4}{ }^{+} \mathrm{-N}, \mathrm{TN}$, and TP was $98.2 \%, 95.7 \%, 95.6 \%$, and 96.2\% (Hai et al., 2015). Combining the two treatment processes, microbial treatment and adsorption, in a SBR was applied for a simulated textile-dyeing wastewater. The results showed that removal efficiency reached to 53$79 \%$, while color removal was rather low (10-18\%)(Santos et al., 2015).

The research also showed that SBR was very effective for $\mathrm{N}$ removal in highly saline wastewaters by partial nitrification and denitrification (She et al., 2016). The performance of SBR was done in this work in the treatment of sewage, medical wastewater and industrial wastewater. Results showed that COD, nitrogen and phosphorus were effectively removed from the three types of wastewater under optimal conditions. This suggested that SBR method could be also applied in the treatment of medical and industrial wastewater.

\section{Materials and methods}

\section{Activated-sludge system}

\section{Sludge cultivation}

Activated sludge in this study was collected from the wastewater treatment plant (Fig.1).

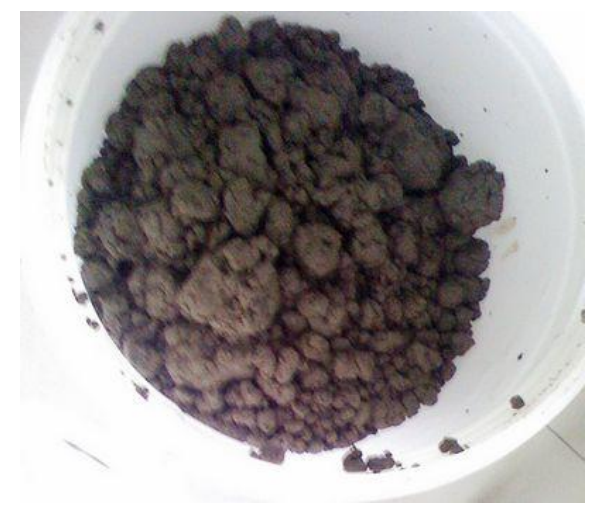

Figure 1. Sludge samples from the wastewater treatment plant

The dry sludge from the wastewater treatment plant was in static culture. Nutrient solution was added to the activated sludge (C: N: P ratio of 100:5:1) and cultured with aeration, so that the growth of microorganisms in the activated sludge was promoted. The nutrient solution used for the cultivation of the sludge was composed of $2.814 \mathrm{~g}$ glucose, $0.48 \mathrm{~g}$ potassium dihydrogen phosphate, and $0.36 \mathrm{~g}$ ammonium chloride, dissolving in $1 \mathrm{~L}$ of water. Maturity of the activated sludge was measured by chemical analysis. The monitoring indicators included settling velocity (SV), sludge volume index (SVI), mixed liquor suspended solids (MLSS), and mixed liquor volatile suspended solids (MLVSS). The microbial phase was determined by microscopic examination.

\section{Sludge acclimation}

After incubation, the sludge was taken into the SBR device (Subsequent description). Lowconcentration wastewater (diluted sewage) was used for sludge cultivation. After 23 hours of aeration and 1 hour of sedimentation, the supernatantwas discarded, and the sludge was added with the same concentration of fresh sewage to continue aeration culture. The growth of 
activated sludge was observed under a microscope. The effluent increased gradually until the concentration reached that of the raw sewage. At the point that the activated sludge was stable, its maturity was determined by microscopy and chemical analysis.

\section{Experimental design}

\section{Experimental model}

The SBR was fabricated from plexiglass with a working volume of $128 \mathrm{~L}$, and the length $\times$ width $\times$ height was $80 \mathrm{~cm} \times 40 \mathrm{~cm} \times 50 \mathrm{~cm}($ Fig. 2$)$. The reactant was mixed with a magnetic stirrer and aerated sufficiently with a compressor. Aeration, stirring and settling can be carried out in the same reactor.Operation time of reaction and precipitation was manually controlled.

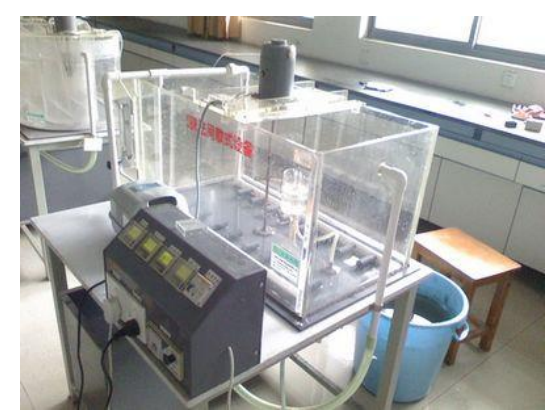

Figure 2. SBR reactor

\section{Wastewater sampling}

Sewage and medical wastewater were taken from student dormitory and medical clinic of the university, respectively. High organic industrial wastewater was self-configured from three kinds of solution as follows: Solution A: $93.8 \mathrm{~g} / \mathrm{L}$ glucose solution (equivalent to COD $100 \mathrm{~g} / \mathrm{L}$ ). Solution B: $\mathrm{K}_{2} \mathrm{HPO}_{4} 320 \mathrm{~g} / \mathrm{L}, \mathrm{KH}_{2} \mathrm{PO}_{4} 160 \mathrm{~g} / \mathrm{L}, \mathrm{NH}_{4} \mathrm{Cl} 120 \mathrm{~g} / \mathrm{L}$. Solution C: $\mathrm{MgSO}_{4} \cdot 7 \mathrm{H}_{2} \mathrm{O} 15.0$ $\mathrm{g} / \mathrm{L}, \mathrm{FeSO}_{4} \cdot 7 \mathrm{H}_{2} \mathrm{O} 0.5 \mathrm{~g} / \mathrm{L}, \mathrm{ZnSO}_{4} \cdot 7 \mathrm{H}_{2} \mathrm{O} 0.5 \mathrm{~g} / \mathrm{L}, \mathrm{CaCl}_{2} 2.0 \mathrm{~g} / \mathrm{L}, \mathrm{MnSO}_{4} \cdot 3 \mathrm{H}_{2} \mathrm{O} \quad 0.5 \mathrm{~g} / \mathrm{L} .10 \mathrm{~mL}$ of each solution was taken and mixed, diluted to $1000 \mathrm{~mL}$ to form the industrial wastewater. Supernatants of the water samples from the SBR model at the beginning and the end of each cycle were taken and analyzed (Table 1). The suspended solids (SS) were so few that could be negligible, so the SS content changes were not considered in the experiment.

The wastewater samples were analyzed for COD, TP, TN, ammonia, MLSS, MLVSS, SV and SVI according to the Standard Methods (NEPA, 2002). All experiments were performed in triplicate.

Table 1. Initial concentrations of various wastewaters

\begin{tabular}{cccccc}
\hline & $\mathrm{TP}(\mathrm{mg} / \mathrm{L})$ & $\mathrm{NH}_{3}-\mathrm{N}(\mathrm{mg} / \mathrm{L})$ & $\mathrm{COD}(\mathrm{mg} / \mathrm{L})$ & $\mathrm{TN}(\mathrm{mg} / \mathrm{L})$ & $\mathrm{pH}$ \\
\hline Sewage & 30.4 & 128 & 234 & 130 & - \\
Medical wastewater & - & 45.1 & 151 & - & 8.18 \\
Industrial wastewater & 14.4 & 36 & 1057 & 43 & - \\
\hline
\end{tabular}

\section{Experimental conditions}

According to SBR biochemical mechanism, experimental conditions were designed as the following three stages: Aerobic aeration-Anoxic mixing-Settling. 
During the aerobic stage, large amounts of organic matter were assimilated by microorganisms for their life activities. The major consumed pollutant was COD. Phosphorus in sewage was also absorbed by phosphorus accumulating organisms (PAO). At anoxic mixing stage, residual free oxygen was consumed.

When organic materials and oxygen were completely consumed, the system entered into the anaerobic stage, and the release of carbon and denitrification by facultative denitrifying bacteria occurred. Phosphorus could be transformed into energy by PAOs for their biosynthesis or into phosphate by acid-producing bacteria to remove phosphorus in the anaerobic state.

Therefore, COD removal occurred in the aerobic stage, while phosphorus removal occurred in anaerobic phase. Different cycle conditions were selected to achieve the best treatment effect. The operating conditions of SBR for treating various wastewaters were shown in Table 2.

Table 2. Design of operating conditions for various wastewaters.

\begin{tabular}{cccccccccc}
\hline & & Sewage & \multicolumn{3}{c}{ Medical wastewater } & \multicolumn{2}{c}{ Industrial wastewater } \\
\hline Cycle & $\begin{array}{c}\text { Aeration } \\
\text { hs }\end{array}$ & $\begin{array}{c}\text { Anoxia } \\
\text { hs }\end{array}$ & $\begin{array}{c}\text { settling } \\
\text { hs }\end{array}$ & $\begin{array}{c}\text { Aeration } \\
\text { hs }\end{array}$ & $\begin{array}{c}\text { Anoxia } \\
\text { hs }\end{array}$ & $\begin{array}{c}\text { settling } \\
\text { hs }\end{array}$ & $\begin{array}{c}\text { Aeration } \\
\text { hs }\end{array}$ & $\begin{array}{c}\text { Anoxia } \\
\text { hs }\end{array}$ & $\begin{array}{c}\text { settling } \\
\text { hs }\end{array}$ \\
\hline 1 & 4 & 4 & 1 & 3 & 2 & 1 & 4 & 4 & 1 \\
2 & 5 & 5 & 4 & 2 & 3 & 1 & 5 & 5 & 2 \\
3 & 4.5 & 4.5 & 2 & 4 & 4 & 1 & 4.5 & 4.5 & 1.5 \\
4 & 3 & 3 & 1.5 & 5 & 5 & 1 & 3 & 3 & 2 \\
5 & 6 & 3 & 5 & 6 & 6 & 1 & 3.5 & 3.5 & 1.5 \\
6 & 7 & 5.5 & 2 & - & - & - & - & - & - \\
\hline
\end{tabular}

\section{Results and Discussion}

\section{Characterization of the activated sludge}

This experiment was to determine the characteristics of the activated sludge throughout adaptation period, logarithmic growth, steady growth and decline phase. The parameters of the activated sludge were shown in Table 3. Early stage means the time after the start-up of sludge incubation in the SBR, while middle stage means the time after aeration for 23 hours and then settling for 1 hour.The MLSS in the early and middle stages of sludge incubation in SBR ranged from $5.82 \mathrm{mg} / \mathrm{L}$ to $12.89 \mathrm{mg} / \mathrm{L}$ and $7.98 \mathrm{mg} / \mathrm{L}$ to $12.98 \mathrm{mg} / \mathrm{L}$, respectively. Corresponding SV ranged from $40 \%$ to $82 \%$ and $31 \%$ to $82 \%$, respectively. The SVI ranged from $62 \mathrm{~mL} / \mathrm{g}$ to 95 $\mathrm{mL} / \mathrm{g}$ and $31 \mathrm{~mL} / \mathrm{g}$ to $75 \mathrm{~mL} / \mathrm{g}$, respectively. The MLVSS in the early and middle stages of sludge incubation in SBR ranged from $4.77 \mathrm{mg} / \mathrm{L}$ to $7.84 \mathrm{mg} / \mathrm{L}$ and $7.98 \mathrm{mg} / \mathrm{L}$ to $12.98 \mathrm{mg} / \mathrm{L}$, respectively. It was noteworthy that the MLVSS was higher in the middle stage than that in the early stage.

Table 3. The parameters of the activated sludge.

\begin{tabular}{cccccccc}
\hline \multicolumn{3}{c}{ In the early stage of sludge incubation } & \multicolumn{3}{c}{ In the middle stage of sludge incubation } \\
\hline SV/\% & $\begin{array}{c}\text { MLSS } \\
/(\mathrm{mg} / \mathrm{L})\end{array}$ & $\begin{array}{c}\text { MLVSS } \\
/(\mathrm{mg} / \mathrm{L})\end{array}$ & $\begin{array}{c}\text { SVI } \\
/(\mathrm{mL} / \mathrm{g})\end{array}$ & SV/\% & $\begin{array}{c}\text { MLSS } \\
/(\mathrm{mg} / \mathrm{L})\end{array}$ & $\begin{array}{c}\text { MLVSS } \\
/(\mathrm{mg} / \mathrm{L})\end{array}$ & $\begin{array}{c}\text { SVI } \\
/(\mathrm{mL} / \mathrm{g})\end{array}$ \\
\hline 55 & 5.82 & 5.44 & 95 & 50 & 7.98 & 7.14 & 75 \\
40 & 6.41 & 5.77 & 62 & 31 & 10.09 & 10.02 & 31 \\
82 & 12.89 & 7.844 & 64 & 65 & 10.17 & 8.44 & 64 \\
- & - & - & - & 50 & 11.91 & 10.97 & 42 \\
- & - & - & - & 82 & 12.89 & 7.84 & 64 \\
\hline
\end{tabular}


In the early stage of sludge incubation, DO concentration was about $2 \mathrm{mg} / \mathrm{L}$. Organic matter was consumed rapidly and the amount of activated sludge increased. In the middle stage, the sludge concentrations significantly increased, and the demands for nutrients and DO also increased. The biological phase in the middle stage of sludge incubation was shown in Fig. 3. Activated sludge grew quickly, and the sludge cultivation was in good condition. Sludge bulking did not appear.

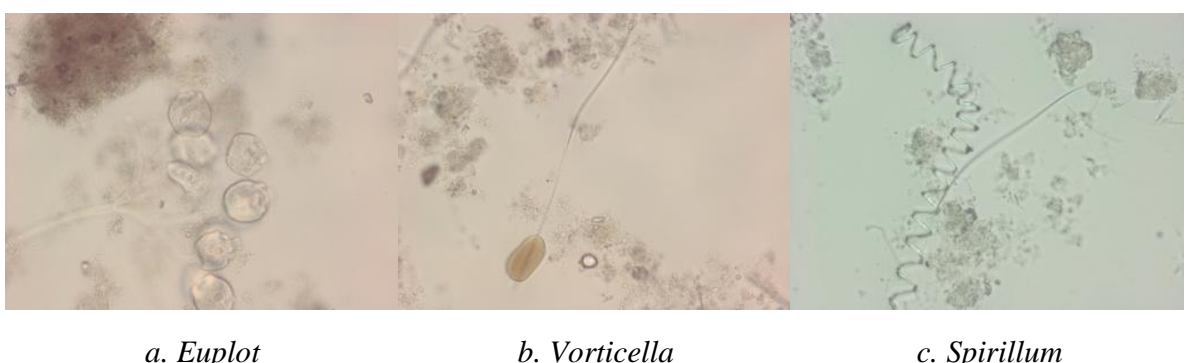

Figure 3. Biological phase in the middle stage of sludge incubation

After 30 days of static culture stage, red nemato deappeared in the activated sludge (Fig. 4), which indicated that the activated sludge had been aging. The activated sludge bulking occurred obviously, and its characteristics greatly reduced. The treatment efficiency of pollutants was not high, so the activated sludge at the middle stage was selected to be used in the experiment.

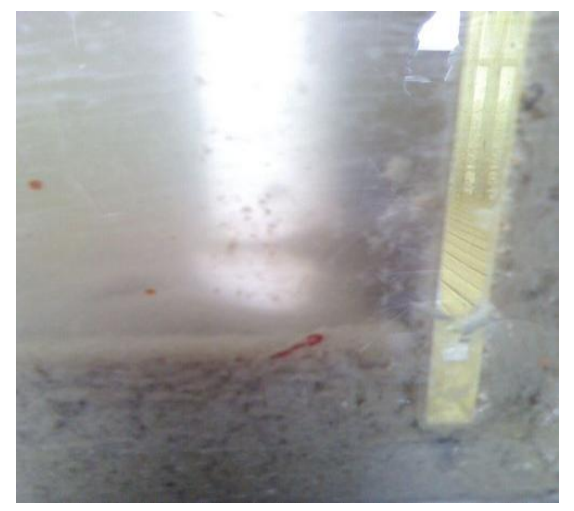

Figure 4. Red nematode in the final stage of sludge incubation.

\section{Pollutant removal efficiency of various wastewaters}

Pollutant removal efficiency of sewage was shown in Fig. 5. When aeration time was 6 hours, the COD removal efficiency was the highest, 94\%. After 6 hours, the COD treatment effect began to decline. Large fluctuations were observed in the nitrogen removal efficiency. The nitrogen removal rate was better under conditions 1,2 and 6 than that under others. Its treatment effect was high when stirring time was 4 hours and 5.5 hours. A 6 hour aeration period was estimated that it was sufficient for microorganisms in the endogenous respiration period, in order to minimize the amount of excess sludge. For the saving of economyand resource, 4 hours was selected as the best condition.

A pilot-scale sequencing batch reactor was also carried on with two phases, anaerobic and aerobic, to removal nitrogen and phosphorus simultaneously. Average removal of COD, TN and TP of sequencing batch reactor reached 95\%, 94\%, and 97\%, respectively (Yin et al., 2015). 

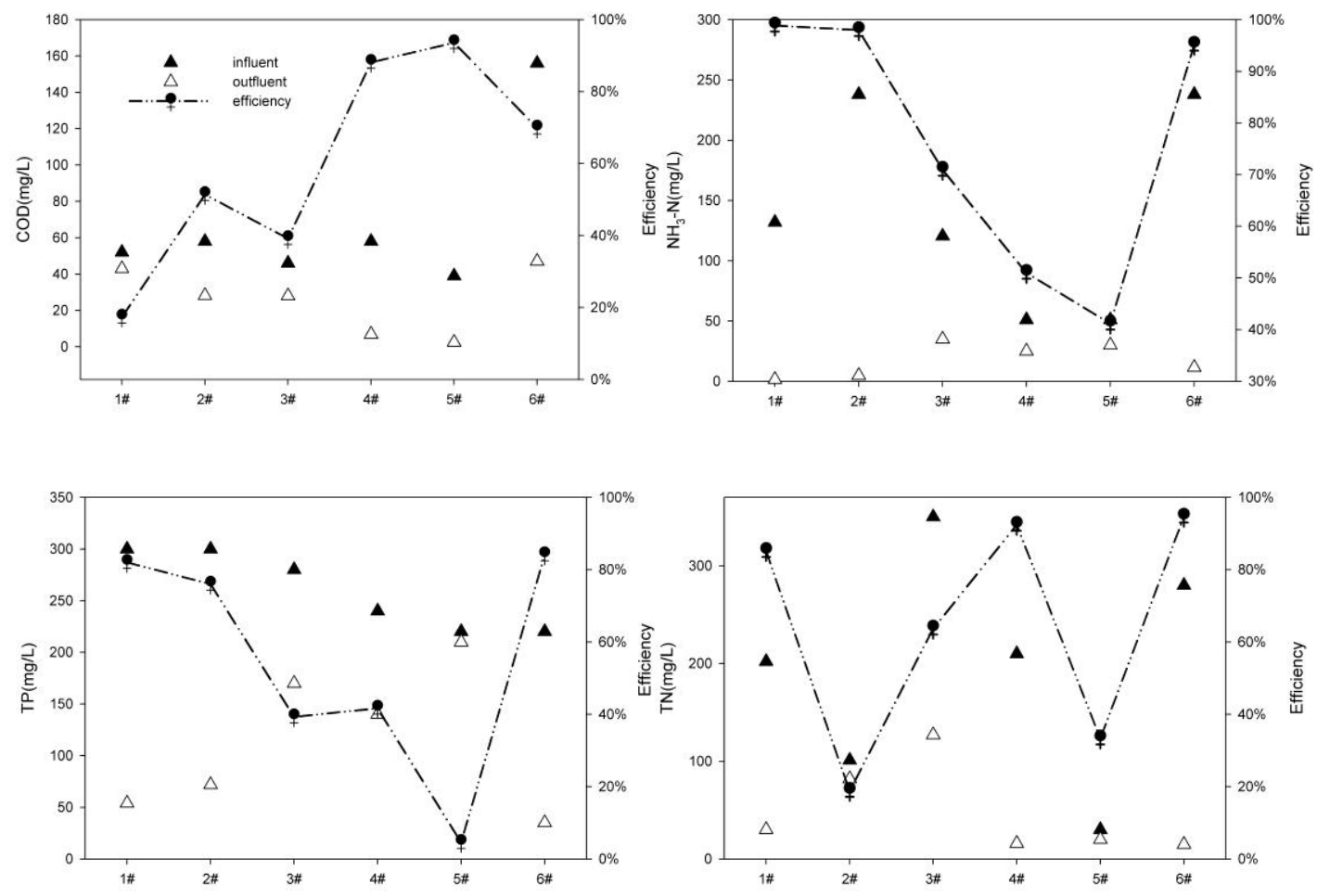

Figure 5. Pollutant removal efficiency of sewage.

The experimental results showed that phosphorus removal rate under the condition of settling for 5 hours was better than that under the other conditions. Considering the actual application, the best settling time was 2 hours.

The pollutant removal efficiency of medical wastewater was shown in Fig. 6. Ammonia and COD removal efficiencies of medical wastewater were high. The influent concentrations were different, but the ammonia removal efficiency did not have much difference among the five conditions. When aeration was 4 hours, anoxia was 4 hours and settling was 1 hour, the ammonia removal efficiency was $59.1 \%$, which was lower than that under other conditions. Meanwhile, when aeration was 5 hours, anoxia was 5 hours and settling was 1 hour, the ammonia removal efficiency was $91.5 \%$, which was the highest in all conditions. After aeration of 3 hours, the ammonia removal efficiency reached $69.7 \%$. However, with continuous aeration, there was little difference in the purification effect. The COD removal efficiency was $85.8 \%$ under condition 4, which was the highest in all conditions. After aeration of 3 hours, the removal rate was $44.3 \%$, which was the lowest in all conditions. The degradation of organic matter was not treated at this moment. SBR was also performed to remove organic matters and nitrogen compounds from medical wastewater. The experimental results elaborated that the removal efficiency of $\mathrm{COD}, \mathrm{NH}_{4}{ }^{+}-\mathrm{N}$ and $\mathrm{NO}_{3}{ }^{-} \mathrm{N}$ were in the range of 88.7-89.3\%, 77.2-96\%, $35.7-92.5 \%$, respectively (Hasan et al., 2016).

The pollutant removal efficiency of the industrial wastewater was shown in Fig.7. The removal efficiency of organic matter, ammonia, total nitrogen was $96.5 \%, 94 \%$ and $91 \%$, respectively after aeration for 4.5 hours, which was the highest in all conditions. The removal rate of total phosphorus was $90-95 \%$ in these working conditions. Notably, when SBR biological treatment process was used for pollutants removal of wastewater, large amounts of excess sludge were produced. This part of excess sludge was discharge into sludge treatment system by sludge pipe. 

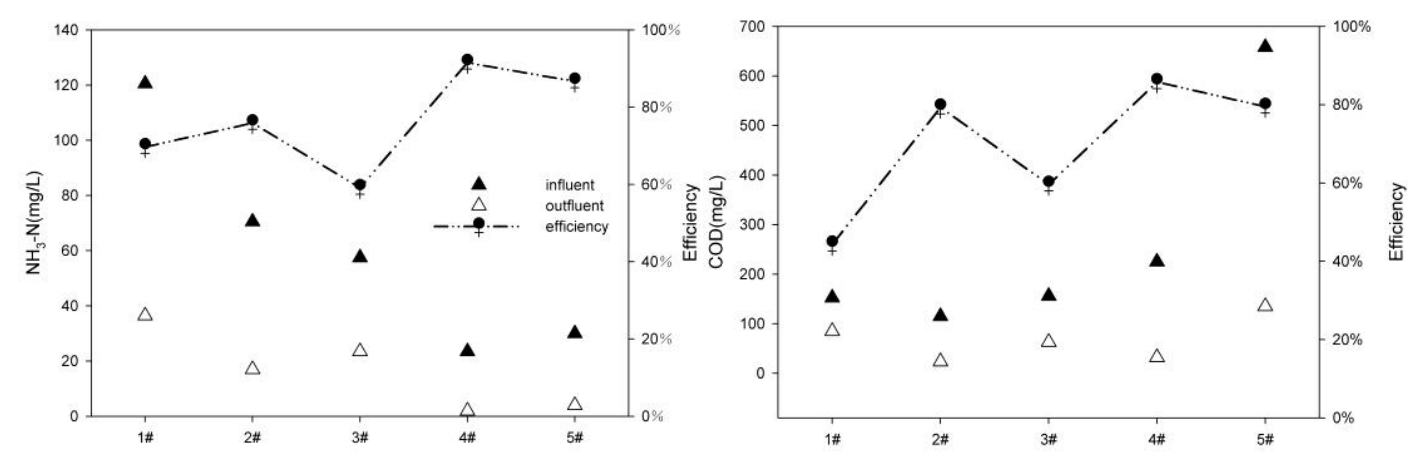

Figure 6. Pollutant removal efficiency of medical wastewater.

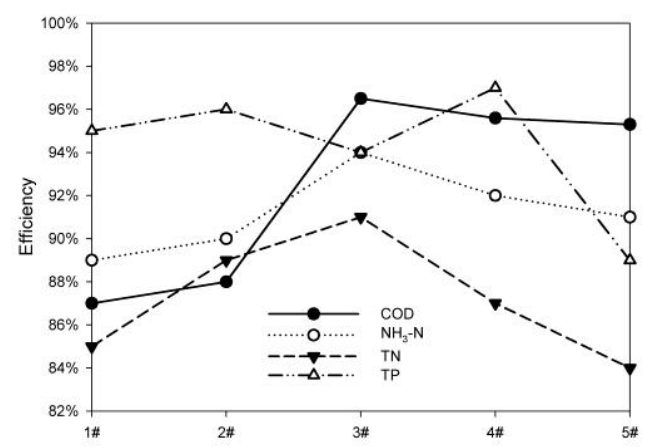

Figure 7. Pollutant removal efficiency of industrial wastewater.

\section{Conclusions}

Activated sludge was cultivated and acclimatized before entering into the SBR. Three kinds of wastewater were selected to compare the pollutant removal efficiencies under different conditions.

The research data showed that, when aeration 7 hours, stirring 5.5 hours, and settling 2 hours in the SBR, purification rates of COD, nitrogen and phosphorus of domestic wastewater were 93\%, 98\% and 83\%, respectively. When aeration 5 hours, stirring 5 hours, and settling 1 hour in the SBR, the purification rates of COD and nitrogen of pharmaceutical wastewater were $86 \%$ and $91 \%$, respectively. When aeration 4 hours, stirring 4 hours, and settling 1 hour in the SBR, the purification rates of COD, nitrogen and phosphorus of simulated industrial wastewater were 97\%, 93\% and 97\%, respectively. Therefore, the purification efficiencies of organic matters, nitrogen compounds and phosphorus by SBR bioreactor were all more than $80 \%$.

Acknowledgements. This research was supported by National Science Foundation of China with the No. 41101465, 41371121 and 41271329, Jiangsu Overseas Research \& Training Program for University Prominent Young \& Middle-aged Teachers and Presidents. 


\section{REFERENCES}

[1] Carucci, A., Lindrea, K., Majone, M., Ramadori, R.(1995):Dynamics of the anaerobic utilization of organic substrates in an anaerobic/aerobic sequencing batch reactor. -Water Science \&Technology 31(2):35-43.

[2] Chiavola, A., Farabegoli, G., Antonetti, F..(2014):Biological treatment of olive mill wastewater in a sequencing batch reactor. -Biochemical Engineering Journal 85:71-78.

[3] Fleming, R. A., Barclay, H. J., Candau, J. N. (2002): Scaling-up an autoregressive timeseries model (of spruce budworm population dynamics) changes its qualitative behaviour. - Ecological Modelling 149(1-2): 127-142.

[4] Gali, A., Dosta, S., Lopez, P., Alvarez,M.(2008): SBR technology for high ammonium loading rates.-Water Science \&Technology 58(2): 467-472.

[5] Giordano, A., Stante, L., Pirozzi, F. Cesaro, R., Bortone, G. (2005): Sequencing batch reactor performance treating PAH contaminated lagoon sediments.-Journal of Hazardous Materials 119:159-166.

[6] Hai, R., He, Y.Q., Wang, X.H., Li, Y. (2015): Simultaneous removal of nitrogen and phosphorus from swinewastewater in a sequencing batch biofilm reactor.-Chinese Journal of Chemical Engineering 23:303-308.

[7] Hasan, H. A., Abdullah, S. R. S., Al-Attabi,A. W. N., Nash, D. A. H., Anuar, N., Rahman, N. A., Titah H. S. (2016):Removal of ibuprofen, ketoprofen, COD and nitrogen compounds frompharmaceutical wastewater using aerobic suspension-sequencing batchreactor (ASSBR). -Separation and Purification Technology 157:215-221.

[8] Jin X., Lo, S.L., Chen, H.M., Ding, K.Q., Gong, R. (2015):Pollutant removal by gravel contact oxidation treatment system in Taipei.-Journal of Residuals Science \&. Technology 12:199-204.

[9] Ketchum, J. (1997):Design and physical features of sequencing batch reactors.-Water Science \&Technology 35 (1): 11-18.

[10] Lamine, M., Bousselmi, L., Ghrabi. A. (2007): Biological treatment of grey water using sequencing batch reactor. -Desalination 215:127-132.

[11] Mace, S.Alvarez, J.M. (2002): Utilization of SBR technonlogy for wastewater treatment: an overview. -Industrial \& Engineering Chemistry Research 41 (23):5539-5553.

[12] N.E.P.A.(2002): Chinese, Water and Wastewater Monitoring Methods, fourth ed.Chinese Environmental Science Publishing House, Beijing.

[13] Ng Wun Jern. (1987):Aerobic Treatment of Piggery Wastewater with the Sequencing Batch Reactor.-Biological Wastes 22:285-294.

[14] Obaja, D., Mace, S., Costa, J., Sans, C.,Alvarez J.M.(2003):Nitrification, denitrification and biological phosphorus removal in piggery wastewater using a sequencing batch reactor. -Bioresource Technology 87:103-111.

[15] Podani, J. (1994): Multivariate Data Analysis in Ecology and Systematics. - SPB Publishing, The Hague.

[16] Rodríguez, D. C., Ramírez, O., Mesa, G. P.(2011): Behavior of nitrifying and denitrifying bacteria in a sequencing batch reactor for the removal of ammoniacal nitrogen and organic matter. -Desalination 273:447-452.

[17] Santos, C.R. S., Rui A.R. B.(2015):Treatment of a simulated textile wastewater in a sequencing batchreactor (SBR) with addition of a low-cost adsorbent.-Journal of Hazardous Materials291:74-82.

[18] Sarioglu, M.(2005): Biological phosphorus removal in a sequencing batch reactor by using pure cultures-Process Biochemistry 40:1599-1603.

[19] She, Z.L., Zhao, L.T., Zhang, X.L., Jin, C.J., Guo, L., Yang, S.Y., Zhao, Y.G. andGao, M.C.(2016): Partial nitrification and denitrification in a sequencing batch reactortreating high-salinity wastewater. -Chemical Engineering Journal 288:207-215. 
[20] Silverstein, A., Schroeder, E. D.(1983):Performance of SBR activated sludge processes with nitrification/denitrification.-Journal of Water Pollution Control Federation 55(4):377-384.

[21] Thompson, J. N. (1984): Insect Diversity and the Trophic Structure of Communities. - In: Huffaker, C. B. (ed.) Ecological Entomology. Wiley-Interscience, New York.

[22] Tóthmérész, B. (1995): Comparison of different methods for diversity ordering. - Journal of Vegetation Science 6: 283-290.

[23] Yin, J., Zhang, P.Y., Li, F., Li, G.P., Hai, B.H.(2015):Simultaneous biological nitrogen and phosphorus removal with asequencing batch reactor-biofilm system.-International Biodeterioration \& Biodegradation 103:221-226. 